\title{
Role of granulocyte-macrophage colony stimulating factor (GM-CSF) in the pathogenesis of adult pulmonary histiocytosis $\mathrm{X}$
}

\author{
Abdellatif Tazi, Marcel Bonay, Anne Bergeron, Martine Grandsaigne, Allan J Hance, \\ Paul Soler
}

\begin{abstract}
Background - Pulmonary histiocytosis X is a disorder characterised by the presence of destructive granulomas preferentially involving distal bronchioles, that contain numerous activated Langerhans' cells. Recent studies have shown that granulocytemacrophage colony stimulating factor (GM-CSF), which is produced by normal bronchiolar epithelium, may play an important part in the distribution and differentiation of Langerhans' cells. The aim of this study was to evaluate the role of this factor in the pathogenesis of pulmonary histiocytosis $\mathrm{X}$.
\end{abstract}

Methods - Four patients with pulmonary histiocytosis $X$ were examined by immunohistochemical techniques for GM-CSF and CD1a surface molecules.

Results - In early lesions the epithelium of bronchioles affected by the disease was strongly positive for GM-CSF and infiltrated by numerous CD1a+ Langerhans' cells organised into granulomas. In contrast, the expression of GM-CSF was substantially lower in bronchioles not affected by the disease, and these bronchioles contained few Langerhans' cells. When destruction by histiocytosis $\mathrm{X}$ lesions was more advanced, only remnants of bronchiolar epithelium could occasionally be identified; these remained strongly reactive for GM-CSF. Langerhans' cells within granulomas also moderately expressed this cytokine.

Conclusions - These results support the hypothesis that GM-CSF could be one of the factors responsible for the local accumulation of lymphostimulatory Langerhans' cells in early lesions of pulmonary histiocytosis $\mathbf{X}$.

(Thorax 1996;51:611-614)

Keywords: histiocytosis X, Langerhans' cells, GM-CSF.

Pulmonary histiocytosis $\mathrm{X}$, also referred to as Langerhans' cell histiocytosis, is a disorder of unknown aetiology characterised by the presence of destructive granulomas containing large numbers of Langerhans' cells which are preferentially located within distal bronchioles. ${ }^{1-5}$ The earliest lesions form adjacent to terminal and respiratory bronchioles and appear to invade the bronchiolar wall in an eccentric fashion. ${ }^{2-5}$ Little is known, however, of the mechanism responsible for the accumulation of Langerhans' cells at these sites. One factor which could be involved in this process is granulocyte-macrophage colony stimulating factor (GM-CSF). This $22 \mathrm{kD}$ glycoprotein is released by various cell types including keratinocytes, tracheal epithelium in rat, and bronchiolar epithelium in normal human lung - all sites where cells of dendritic lineage are present. ${ }^{6-8}$ This cytokine is also produced by some lung cancers, and a close correlation has been found between the intensity of production of GM-CSF and the number of Langerhans' cells infiltrating the tumour cells. ${ }^{8}$ Finally, the injection of recombinant GM-CSF into the skin of patients with leprosy induces the selective recruitment of Langerhans' cells into the dermis ${ }^{9}$ and, when cultured in vitro in the presence of both GM-CSF and tumour necrosis factor $\alpha$ (TNF- $\alpha)$, cord blood cells differentiate into mature Langerhans' cells. ${ }^{10}$ Thus, GM-CSF seems to be involved in the regulation of the number and distribution of Langerhans' cells in human tissues.

Since pulmonary histiocytosis $\mathrm{X}$ is characterised by the infiltration of the wall of respiratory bronchioles by Langerhans' cells, we hypothesised that an increase in the local production of GM-CSF could participate in the accumulation of numerous Langerhans' cells observed in these lesions. To test this hypothesis we used immunohistochemical techniques and specific antibodies to evaluate the production of GM-CSF by bronchiolar epithelium involved by Langerhans' cell granulomas. Because histiocytosis $\mathrm{X}$ lesions are focally distributed, ${ }^{1-5}$ we compared the amount of GM-CSF observed within these lesions with that present in bronchioles from the same individual that were not affected by the pathological process.

Methods

PATIENTS

Four patients (three men) with pulmonary histiocytosis X of mean (SD) age 26 (8) years, all of whom were current smokers, were evaluated. Lung tissue was obtained at the time of open lung biopsy performed to establish the diagnosis.

HISTOPATHOLOGICAL AND

IMMUNOHISTOCHEMICAL ANALYSIS

For light and electron microscopic examination tissue specimens were processed by routine techniques. For immunohistochemical stain- 

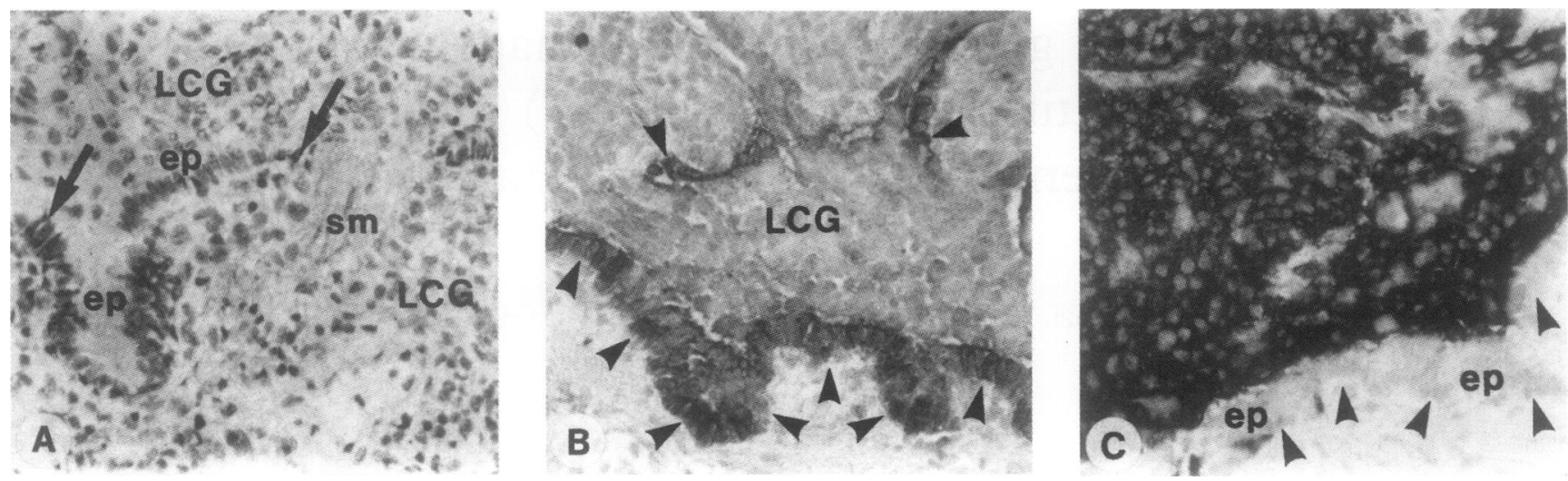

Figure 1 Adjacent sections of a small bronchiole partially invaded by a histiocytosis $X$ lesion. (A) Conventional light micrograph showing remnants of bronchiolar structures within the Langerhans' cell granuloma (LCG). A large portion of the epithelium (ep), delimited by arrows, and smooth muscle bundles (sm) are still recognisable (H and E stain). (B) Immunostaining with anti-GM-CSF antibody showing that bronchiolar epithelial cells, delineated by arrow heads, are strongly positive. Cells forming the granuloma (LCG) are packed close to the epithelium. They are themselves moderately positive for GM-CSF. (C) Immunostaining with anti-CD1 a antibody showing that cells forming the granuloma are essentially CD1 a + Langerhans' cells. The arrow heads delineate the bronchiolar epithelium. Original magnification $\times 250$, reduced to $65 \%$ in origination.

ing, tissue fragments were frozen by immersion in liquid nitrogen, lyophilised, and embedded in paraffin as previously described. ${ }^{8}$ A sheep anti-human GM-CSF polyclonal antiserum (National Institute for Biological Standards and Control, Hertfordshire, UK) was used to identify this cytokine. The specificity of this antibody has been previously described. ${ }^{8} \mathrm{~A}$ monoclonal antibody recognising CDla surface molecules (OKT6, Ortho Diagnostics, Raritan, New Jersey, USA) was used to identify Langerhans' cells. Other monoclonal antibodies used were: Leu-4 (recognising all CD3 + T cells, Becton Dickinson, Mountain View, California, USA); $\beta \mathrm{F} 1$ (recognising all $\alpha / \beta \mathrm{T}$ cells, $\mathrm{T}$ Cell Sciences, Cambridge, Massachusetts, USA); TCR $\delta 1$ (recognising all $\gamma / \delta$ T cells, T Cell Sciences); Leu-3a $+b$ Multiclone (recognising $\mathrm{CD} 4+\mathrm{T}$ cells, Becton Dickinson), and OKT8 (recognising CD8 $+\mathrm{T}$ cells, Ortho Diagnostics).

Sections were reacted with appropriate dilutions of antibodies and positive cells revealed by reaction with alkaline phosphatase antialkaline phosphatase antibody complexes (APAAP kit system; Dakopatts, Glostrup, Denmark). Sections incubated with sheep anti-GM-CSF antibody were reacted with a biotinylated secondary antibody (Multi Link, Dakopatts) and alkaline phosphatase conjugated streptavidin (Caltag, San Francisco, California, USA). Positive cells were revealed by reaction with the fast red substrate (Dakopatts).

\section{Results}

PATHOLOGICAL FINDINGS

Typical histiocytosis $\mathrm{X}$ granulomatous lesions were observed in all samples used for immunohistochemical studies. These lesions were focal and consisted of cell aggregates of variable size. Characteristic Langerhans' cells, easily recognised by their deeply indented nuclei and faintly acidophilic cytoplasm, were abundant in all lesions. These cells were unequivocally identified by the intensive expression of CD1a antigens and the presence of intracytoplasmic
Birbeck granules by electron microscopy (not shown).

In three cases histiocytosis $\mathrm{X}$ lesions, although focal, were of considerable size and distributed throughout the biopsy samples. In these cases it was often difficult to establish that a given granulomatous lesion had formed adjacent to bronchioles because the destructive lesions had completely replaced pre-existing parenchyma. In some lesions, however, remnants of bronchiolar structures - that is, short stalks of epithelium, smooth muscle bundles, and/or lymphatics or arterioles close to or within the granulomas - indicated that the lesions were bronchocentric. In the remaining patient, however, only small and scattered granulomas invading respiratory bronchioles were present. These small granulomas undoubtedly represented very early lesions, since the bronchioles they invaded were only partially destroyed and large portions of epithelium were still recognisable (fig 1A). In samples from all patients bronchioles not affected by the pathological process were usually normal (fig 2A), although some bronchioles showed minor alterations such as intraluminal accumulation of mucus, alveolar macrophages and lymphocytes, probably due to cigarette smoking.

GM-CSF PRODUCTION IN LUNG TISSUE FROM PATIENTS WITH HISTIOCYTOSIS $\mathrm{x}$

In the specimen containing very early lesions (in which the epithelium of involved bronchioles was partly intact), the epithelial cells remaining at sites of involvement were strongly stained with the anti-GM-CSF antibody (fig 1B). These GM-CSF positive cells were, in all lesions, closely associated with numerous CD1a + Langerhans' cells organised into granulomas (fig 1C). In three other cases, remnants of bronchiolar epithelium were systematically sought within histiocytosis $\mathrm{X}$ lesions and identified in only one specimen. In this case, the residual bronchiolar epithelial cells, although present in small numbers, also 

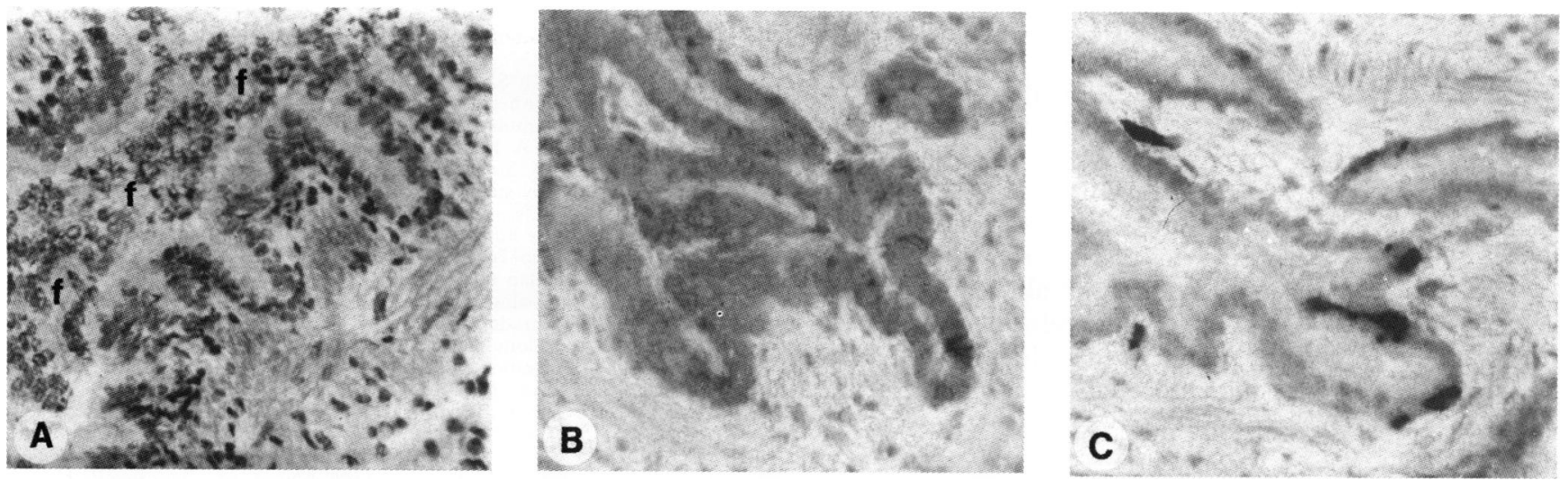

Figure 2 Adjacent sections of a small bronchiole spared by the disease. (A) Conventional light micrograph showing minor alterations of the bronchiolar wall. The lumen is filled with epithelial foldings $(f)$ cut tangentially ( $H$ and $E$ stain). (B) Immunostaining with anti-GM-CSF antibody. The epithelial cells are substantially less positive than those in adjacent histiocytosis X lesions. (C) Immunostaining with anti-CD1a antibody. Few CD1a + Langerhans' cells are present within the epithelium. Original magnification $\times 250$, reduced to $65 \%$ in origination.

strongly expressed GM-CSF (fig 3). In contrast, the intensity of immunostaining for GM$\mathrm{CSF}$ was substantially lower in bronchiolar epithelial cells not affected by the pathological process (fig 2B) and similar to that observed in lung tissue from control subjects (data not shown). The difference in GM-CSF expression between bronchiolar epithelial cells within granulomatous lesions and normal bronchiolar epithelium was particularly easy to appreciate when diseased and non-diseased epithelia present in the same section were compared. Normal bronchiolar epithelium contained few CDla + Langerhans' cells (fig 2C).

Interestingly, Langerhans' cells in histiocytosis $\mathrm{X}$ lesions were moderately positive for GM-CSF (fig 1B) and were associated with numerous lymphocytes expressing the CD3, $\alpha / \beta$ TCR,$+ \mathrm{CD} 4+$ phenotype, whereas few lymphocytes were observed within bronchioles not involved by histiocytosis $\mathrm{X}$ lesions (not shown).

\section{Discussion}

This study shows that, in the earliest histiocytosis X lesions, characterised by small Langerhans' cell granulomas that only partially invade the bronchiolar walls, epithelial cells are intensely positive for GM-CSF and closely

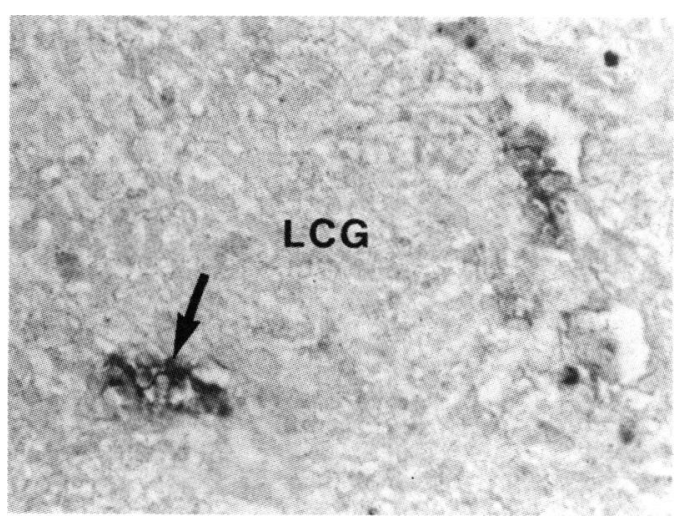

Figure 3 Small bronchiole almost completely destroyed by a Langerhans' cell granuloma (LCG). Only remnants of epithelium, strongly positive for GM-CSF (arrow), are still recognisable. Original magnification $\times 250$, reduced to $65 \%$ in origination. associated with CD1a + Langerhans' cells. In contrast, adjacent bronchioles in these patients that are not affected by the pathological process produce less GM-CSF and contain few Langerhans' cells.

The mechanism responsible for this increased production of GM-CSF remains to be established. Given the strong association between pulmonary histiocytosis $\mathrm{X}$ and cigarette smoking in adult patients, ${ }^{1-5}$ it is tempting to suggest that smoking-induced alterations in the bronchiolar epithelium could lead to the expression of increased amounts of GM-CSF and thereby predispose to granuloma formation adjacent to these abnormal airway cells. Whether bronchiolar epithelial cells of children and non-smoking adults with pulmonary histiocytosis $\mathrm{X}$ produce large amounts of GMCSF for other reasons remains to be evaluated. It is noteworthy that bronchiolar epithelial cells are rapidly destroyed by the granulomatous process, a finding confirmed here. Thus, GMCSF production by these cells cannot sustain Langerhans' cells at these sites. In the present study, Langerhans' cells in histiocytosis $\mathrm{X}$ lesions were found to express GM-CSF moderately in all samples evaluated. Thus, autocrine production of GM-CSF by Langerhans' cells themselves could play a part in the maintenance of granulomas.

We have reported ${ }^{11}$ that close contacts between Langerhans' cells and T lymphocytes, similar to those observed in hypersensitivity reactions, ${ }^{12}$ are present in pulmonary histiocytosis $\mathrm{X}$ granulomas, and others have shown that both cell types are activated in these lesions. ${ }^{13}$ In contrast, previous studies have suggested that normal intraepithelial dendritic cells in rodents, the equivalent to human Langerhans' cells, although able to capture and process foreign antigens efficiently, appear to have low intrinsic lymphostimulatory activity. ${ }^{14}$ These findings suggest that normal lung Langerhans' cells, as Langerhans' cells in other tissues, may be poorly equipped to stimulate lymphocyte proliferation within the lung. In this context, GM-CSF has been shown strongly to upregulate the lymphostimulatory activity of Langerhans' cells in vitro. ${ }^{15-19}$ Thus, GM-CSF may play a dual role in the pathogenesis of 
histiocytosis $\mathrm{X}$ by promoting both the accumulation of Langerhans' cells and by inducing the lymphostimulatory properties of these cells, thereby permitting lymphocyte activation within the lesions.

Recent studies have shown that Langerhans' cells in lesions from patients with both diffuse and localised forms of histiocytosis $\mathrm{X}$ are of clonal origin, ${ }^{20}$ although the existence of clonal Langerhans' cells in pulmonary histiocytosis X has not been evaluated. Nevertheless, a number of clinical and pathological features of isolated pulmonary histiocytosis $\mathrm{X}$ in adults suggest that this disease does not merely result from the malignant transformation of Langerhans' cells, including the strong association of pulmonary histiocytosis X (but not other forms of histiocytosis $\mathrm{X}$ ) with cigarette smoking, the strictly bronchocentric distribution of the granulomas, and the virtual absence of Langerhans' cells in end stage lesions. Thus, if clonal Langerhans' cells are present in pulmonary histiocytosis $\mathrm{X}$, these cells are unlikely to be autonomous malignant cells ${ }^{21}$ but rather subject to local factors that modify their behaviour. Our results suggest that increased production of GM-CSF by bronchiolar epithelium may contribute to the focal accumulation of Langerhans' cells in the course of granuloma formation in adults with histiocytosis X. It is probable that GM-CSF is not the only factor contributing to accumulation of Langerhans' cells in histiocytosis $\mathrm{X}$. Thus, other cytokines known to influence the growth, survival, and differentiated state of cells of dendritic lineage $\mathrm{e}^{1617192223}$ can also be produced by lung epithelial cells and may also be involved in the pathogenesis of pulmonary histiocytosis $\mathrm{X}$.

1 Friedman PJ, Liebow AA, Sokoloff J. Eosinophilic granuloma of the lung. Clinical aspects of primary pulmonary histiocytosis in the adult. Medicine 1981;60:385-96.

2 Colby TV, Lombard C. Histiocytosis X in the lung. Hum Pathol 1983;4:847-56.

3 Soler P, Kambouchner M, Valeyre D, Hance AJ. Pulmonary Langerhans' cell granulomatosis. Annu Rev Med 1992;43: 105-15.

4 Travis WD, Borok Z, Roum JH, Zhang J, Feuerstein I, Ferrans VJ, et al. Pulmonary Langerhans' cell granulomatosis (histiocytosis X). A clinicopathological study ulomatosis (histiocytosis X). A clinicopathological
of 48 cases. Am $₹$ Surg Pathol 1993;17:971-86.

5 Tazi A, Hance AJ. Pulmonary histiocytosis X. In: Walters EH, du Bois RM, eds. Immunology and management of interstitial lung diseases. London: Chapman \& Hall, 1995: interstitial

6 Kupper. TS, Lee F, Coleman D, Chodakewitz J, Flood P, Horowitz M. Keratinocyte derived T-cell growth factor
(KTGF) is identical to granulocyte-macrophage colonystimulating factor (GM-CSF). F Invest Dermatol 1988;91: stimulating.

7 Smith SM, Lee DKP, Lacy J, Coleman DL. Rat tracheal epithelial cells produce granulocyte/macrophage colony stimulating factor. Am $\mathcal{F}$ Respir Cell Mol Biol 1990;2:59-68.

8 Tazi A, Bouchonnet F, Grandsaigne M, Boumsell L, Hance AJ, Soler P. Evidence that granulocyte-macrophage colony-stimulating factor regulates the distribution and differentiated state of dendritic cells/Langerhans' cells in the human lung and lung cancers. F Clin Invest 1993;91: 566-76.

9 Kaplan G, Walsh G, Guido LS, Meyer P, Burkhardt RA, Abalos RM, et al. Novel responses of human skin to intradermal recombinant granulocyte/macrophagecolony-stimulating factor: Langerhans' cell recruitment, colony-stimulating factor: Langerhans' cell recruitment, Exp Med 1992;175:1717-28.

10 Caux C, Dezutter-Dambuyant C, Schmitt D, Banchereau J. GM-CSF and TNF- $\alpha$ cooperate in the generation of dendritic Langerhans' cells. Nature 1992;369:258-61.

11 Tazi A, Bonay M, Grandsaigne M, Battesti JP, Hance AJ, Soler P. Surface phenotype of Langerhans' cells and lymphocytes in granulomatous lesions from patients with pulmonary histiocytosis X. Am Rev Respir Dis 1993;147: 1531-6.

12 Enk AH, Katz SI. Early molecular events in the induction phase of contact sensitivity. Proc Natl Acad Sci USA 1992; 89:1389-402.

13 Colasante A, Poletti V, Rosini S, Farracini R, Musiani P. Langerhans' cells in Langerhans' cell histiocytosis and peripheral adenocarcinomas of the lung. Am Rev Respir Dis 1993;148:752-9.

14 Gong JL, McCarthy KM, Telford J, Tamatani T, Miyasaka $\mathrm{M}$, Schneeberger EE. Intraepithelial airway dendritic cells: a distinct subset of pulmonary dendritic cells obtained by microdissection. f Exp Med 1992;1 15:797-807.

15 Witmer-Pack MD, Olivier W, Valinsky J, Schuler G, Steinman RM. Granulocyte/macrophage colony-stimulating factor is essential for the viability and function of cultured murine epidermal Langerhans' cells. 7 Exp Med 1987;166:1484-98.

16 Heufler C, Koch F, Schuler G. Granulocyte/macrophage colony-stimulating factor and interleukin 1 mediate the maturation of murine epidermal Langerhans' cell into maturation of murine epidermal Langerhans' cell into potent immunostim

17 Koch F, Heufler C, Kämgen E, Schneeweiss D, Böck G, Schuler $\mathrm{G}$. Tumor necrosis factor $\alpha$ maintains the viability of murine epidermal Langerhans' cells in culture but in contrast to granulocyte/macrophage colony-stimulatin factor, without inducing their functional maturation. $f$ Exp Med 1990;171:159-71.

18 Markowicz S, Engleman E. Granulocyte-macrophage colony-stimulating factor promotes differentiation and survival of human peripheral blood dendritic cells in vitro. $\mathcal{f}$ Clin Invest 1990;85:955-61.

19 Sallusto F Lanzavecchia A. Efficient presentation of soluble antigen by cultured human dendritic cells is maintained by granulocyte/macrophage colony-stimulating factor plus by granulocyte/macrophage colony-stimulating factor plus interleukin 4 and downregulated
x. $₹ \operatorname{Exp}$ Med 1994;179:1109-18.

20 Willman CL, Busque L, Griffith BB, Favara BE, McClain $\mathrm{KL}$, Duncan $\mathrm{MH}$, et al. Langerhans'-cell histiocytosi (histiocytosis $\mathrm{X}$ ) - a clonal proliferative disease. $N$ Engl f Med 1994;331:154-60.

21 Beverley PCL, Abbas AK. The scientific challenge of Langerhans' cell histiocytosis. Br f Cancer 1994;70:S61-3.

22 Demidem A, Taylor JR, Grammer SF, Streilein JW. Influence of microenvironmental factors on human Influence of microenvironmental factors on human Langerhans'

23 Enk AH, Angeloni VL, Udey MC, Katz SI. An essential role for Langerhans' cell-derived IL-1 $\beta$ in the initiation of primary immune responses in skin. F Immunol 1993 150:3698-704. 